\title{
Risco cardiovascular em pacientes com doença periodontal
}

\author{
Cardiovascular risk in patients with periodontal disease \\ Riesgo cardiovascular en pacientes con enfermedad periodontal
}

Recebido: 03/02/2022 | Revisado: 14/02/2022 | Aceito: 17/02/2022 | Publicado: 25/02/2022

Emmanuel Nunes de Oliveira ORCID: https://orcid.org/0000-0001-6063-3772 Universidade Federal de Campina Grande, Brasil

E-mail: emmanueloliveira2@gmail.com

Sérvulo da Costa Rodrigues Neto ORCID: https://orcid.org/0000-0002-3823-5759 Universidade Federal de Campina Grande, Brasil

E-mail: servulorodriguesneto@gmail.com

Byanca Andrade Martins

ORCID: https://orcid.org/0000-0003-0733-3249

Universidade Federal de Campina Grande, Brasil

E-mail: byanca.guilherme@gmail.com

Ismael Lima Silva

ORCID: https://orcid.org/0000-0002-5661-9633

Universidade Federal de Campina Grande, Brasil

E-mail: ismaellms839@gmail.com

Roberto de Lucena Jerônimo

ORCID: https://orcid.org/0000-0002-4670-8018

Universidade Federal de Campina Grande, Brasil

E-mail: robertufuzileiro@hotmail.com

Alessandro Marques de Souza Júnior

ORCID: https://orcid.org/0000-0002-6381-236X

Universidade Federal de Campina Grande, Brasil

E-mail: alessandromarquesjr@gmail.com

João Nilton Lopes de Sousa

ORCID: https://orcid.org/0000-0003-3726-386X

Universidade Federal de Campina Grande, Brasil

E-mail: jnlopesodonto@gmail.com

Abrahão Alves de Oliveira Filho

ORCID: https://orcid.org/0000-0002-7466-9933

Universidade Federal de Campina Grande, Brasil

E-mail: abrahao.farm@gmail.com

Elizandra Silva da Penha

ORCID: https://orcid.org/0000-0001-6264-5232 Universidade Federal de Campina Grande, Brasil

E-mail: elizandrapenha@ @otmail.com

Maria Angélica Sátyro Gomes Alves

ORCID: https://orcid.org/0000-0003-3329-8360

Universidade Federal de Campina Grande, Brasil

E-mail: angelicasatyro@ @otmail.com

\section{Resumo}

Objetivo: Esta pesquisa avaliou o risco cardiovascular de pacientes com doença periodontal, conforme seus diferentes níveis de severidade, comparando-os com pacientes de periodonto saudável. Metodologia: A pesquisa foi realizada com pacientes da Clínica Escola Odontológica da UFCG, campus Patos-PB, sendo eles divididos nos grupos Doença Periodontal (DP) e Grupo Controle (GC). O grupo DP foi subdividido em pacientes com Gengivite, com Periodontite Localizada e com Periodontite Generalizada. Amostras de sangue foram coletadas para análise dos níveis séricos da Proteína C-Reativa (PCR), por meio do método ultrassensível. Resultados: Dos 66 participantes, verificou-se que a maioria era do gênero feminino (54,54\%). A idade média foi de 32,37 $\pm 2,41$ anos para o grupo DP e de 24,08 $\pm 1,74$ anos para o GC. Níveis séricos de PCR foram mais elevados no Grupo DP $(6,09 \pm 1,34 \mathrm{mg} / \mathrm{l} ; \mathrm{n}=30)$ quando comparados ao GC $(2,21 \pm 0,23 \mathrm{mg} / \mathrm{l} ; \mathrm{n}=36)$. Os subgrupos com Gengivite $(6,95 \pm 1,99 \mathrm{mg} / \mathrm{l} ; \mathrm{n}=22)$ e com Periodontite Localizada $(11,82 \pm 5,27 \mathrm{mg} / \mathrm{l} ; \mathrm{n}=5)$ apresentaram valores de PCR significantemente maiores que aqueles do GC $(2,21 \pm 0,23$ $\mathrm{mg} / \mathrm{l} ; \mathrm{n}=36)$. Não foram observadas diferenças entre os valores do grupo com Periodontite Generalizada $(2,98 \pm 1,63$ $\mathrm{mg} / \mathrm{l} ; \mathrm{n}=3$ ) em relação ao grupo controle. Conclusão: Concluiu-se que pacientes com doença periodontal apresentaram níveis de PCR mais elevados, quando em comparação aos pacientes do periodonto saudável, o que demonstra uma maior propensão ao desenvolvimento de cardiopatias por indivíduos com periodontopatias. 
Palavras-chave: Doença periodontal; Proteína C-reativa; Risco cardiovascular.

\begin{abstract}
Objective: This research evaluated the cardiovascular risk of patients with periodontal disease, according to their different levels of severity, comparing them with healthy periodontal patients. Methodology: The research was carried out with patients from the Clínica Escola Odontológica da UFCG, campus Patos-PB, being divided into the groups Periodontal Disease (PD) and Control Group (CG). The DP group was subdivided into patients with Gingivitis, Localized Periodontitis and Generalized Periodontitis. Blood samples were collected for analysis of serum levels of CReactive Protein (CRP), using the ultra-sensitive method. Results: Of the 66 participants, it was found that the majority were female $(54,54 \%)$. The mean age was $32,37 \pm 2,41$ years for the DP group and 24,08 $\pm 1,74$ years for the CG. Serum CRP levels were higher in Group DP $(6,09 \pm 1,34 \mathrm{mg} / \mathrm{l} ; \mathrm{n}=30)$ when compared to CG $(2,21 \pm 0,23 \mathrm{mg} / \mathrm{l} ; \mathrm{n}=$ 36). The subgroups with Gingivitis $(6,95 \pm 1,99 \mathrm{mg} / \mathrm{l} ; \mathrm{n}=22)$ and with Localized Periodontitis $(11,82 \pm 5,27 \mathrm{mg} / 1 ; \mathrm{n}=$ 5) had CRP values significantly higher than those of the CG $(2,21 \pm 0,23 \mathrm{mg} / \mathrm{l} ; \mathrm{n}=36)$. There were no differences between the values of the group with Generalized Periodontitis $(2,98 \pm 1,63 \mathrm{mg} / \mathrm{l} ; \mathrm{n}=3)$ compared to the control group. Conclusion: It was concluded that patients with periodontal disease had higher levels of CRP when compared to patients of the healthy periodontium, statistically supporting a greater propensity for the development of heart diseases by individuals with periodontopathies.
\end{abstract}

Keywords: Periodontal disease; C-Reactive protein; Cardiovascular risk.

\title{
Resumen
}

Objetivo: Esta investigación evaluó el riesgo cardiovascular de pacientes con enfermedad periodontal, de acuerdo con sus diferentes niveles de gravedad, comparándolos con pacientes periodontales sanos. Metodología: La investigación se realizó con pacientes de la Clínica Escola Odontológica de UFCG, campus Patos-PB, dividiéndose en los grupos de Enfermedad periodontal (EP) y Grupo de control (CG). El grupo DP se subdividió en pacientes con gingivitis, periodontitis localizada y periodontitis generalizada. Se recogieron muestras de sangre para analizar los niveles séricos de proteína C reactiva (PCR), utilizando el método ultrasensible. Resultados: De los 66 participantes, se encontró que la mayoría eran mujeres (54,54\%). La edad media fue de 32,37 $\pm 2,41$ años para el grupo DP y 24,08 $\pm 1,74$ años para el CG. Los niveles séricos de PCR fueron más altos en el grupo DP $(6,09 \pm 1,34 \mathrm{mg} / \mathrm{l} ; \mathrm{n}=30)$ en comparación con el CG $(2,21 \pm 0,23 \mathrm{mg} / \mathrm{l} ; \mathrm{n}=36)$. Los subgrupos con Gingivitis $(6,95 \pm 1,99 \mathrm{mg} / \mathrm{l} ; \mathrm{n}=22)$ y con Periodontitis Localizada $(11,82 \pm 5,27 \mathrm{mg} / \mathrm{l} ; \mathrm{n}=5)$ tuvieron valores de PCR significativamente más altos que los del CG $(2,21 \pm 0,23 \mathrm{mg} / \mathrm{l} ; \mathrm{n}=$ $36)$. No hubo diferencias entre los valores del grupo con periodontitis generalizada $(2,98 \pm 1,63 \mathrm{mg} / \mathrm{l} ; \mathrm{n}=3) \mathrm{en}$ comparación con el grupo control. Conclusión: Se concluyó que los pacientes con enfermedad periodontal tenían niveles más altos de PCR en comparación con los pacientes del periodonto sano, lo que respalda estadísticamente una mayor propensión al desarrollo de enfermedades cardíacas en individuos con periodontopatías.

Palabras clave: Enfermedad periodontal; Proteína C-reactiva; Riesgo cardiovascular.

\section{Introdução}

A doença periodontal é uma patologia que atinge as estruturas de suporte e sustentação do elemento dentário, sendo provocada por estímulos vindos de microorganismos presentes no biofilme periodontopatogênico, ocasionando uma resposta inflamatória destrutiva por parte do hospedeiro, resultando na perda progressiva da inserção periodontal e aumentando da possibilidade de perda dentária (Preshaw \& Taylor, 2011).

A associação entre a doença periodontal e certas condições sistêmicas tem, recentemente, recebido bastante atenção por parte dos profissionais da área da saúde, devido a possibilidade da doença periodontal poder atuar como um dos diversos fatores de risco para o desenvolvimento de doenças cardiovasculares (Bezerra et al., 2008).

A inflamação periodontal não se limita apenas aos tecidos periodontais, desta forma, bactérias e mediadores químicos do processo inflamatórios podem entrar na corrente sanguínea e induzir inflamação (Linden et al., 2013). A Proteína C-Reativa é um reagente de fase aguda inespecífico, produzido pelo fígado em resposta a diversos estímulos inflamatórios, tendo seus níveis elevados na doença periodontal (Bansal et al., 2014). O aumento da sua concentração durante processos inflamatórios é uma característica amplamente utilizada para propósitos de avaliação clínica (Black et al., 2004).

A concentração sérica de PCR é um importante método de avaliação de risco cardiovascular. Segundo a American Heart Association, valores de PCR superiores a 3,0 mg/l dessa proteína no sangue indicam elevado risco de eventos cardiovasculares, como por exemplo o infarto agudo do miocárdio (Goff et al., 2014). 
Muitos estudos epidemiológicos demonstraram que os níveis séricos de PCR se encontram elevados em pacientes com periodontite crônica. Contudo, nem todos os estudos relataram uma associação entre doença periodontal e PCR. Esses dados podem refletir diferenças na severidade da doença periodontal e da sua progressão em diferentes populações de estudo (Bansal et al., 2014).

A Sociedade Brasileira de Cardiologia considera a periodontite como um indicador para o estado de saúde cardiovascular (Simão et al., 2013). Estudos recentes relacionam os maiores níveis séricos de PCR com um maior risco de alterações cardiovasculares (Chen et al., 2018). A doença periodontal foi ainda significativamente associada ao diabetes, doença coronariana, demonstrando altos níveis de PCR e interleucina 6 (IL-6), estando ainda a forma mais severa da doença associada ao acidente vascular cerebral (Li et al., 2016).

As doenças cardiovasculares constituem um grupo de doenças progressivas e crônicas, caracterizadas pela formação de ateroma no interior das artérias grandes e médias, caracterizando a formação da aterosclerose. Isso produz a redução do lúmen desses vasos e predispõe à trombose e a eventos obstrutivos e isquêmicos. Esses eventos podem ocorrer cronicamente ou precipitar um evento oclusivo repentino (Bascones-Martínez et al., 2017).

Esta pesquisa objetivou investigar a presença de risco de doença cardiovascular em pacientes com doença periodontal, de acordo com seus diferentes níveis de severidade, comparando-a com o grupo de pacientes saudáveis. Por intermédio da mensuração dos níveis séricos da PCR nesses indivíduos, para posterior análise comparativa entre os grupos estudados, relacionando os dados obtidos com o risco cardiovascular inerente a cada grupo.

\section{Metodologia}

\subsection{Classificação da pesquisa}

Este estudo foi do tipo quantitativo, transversal e experimental (Estrela, 2018).

\subsection{Caracterização da amostra}

O grupo estudado foi composto por pacientes atendidos na Clínica-Escola do Curso de Odontologia da Universidade Federal de Campina Grande. Foi utilizada uma amostra de conveniência, composta por um total de 66 indivíduos, onde foram coletadas amostras de sangue desses participantes. Foram avaliados os dados de condição de saúde bucal da Clínica de Periodontia, sendo a divisão dos grupos estudados realizada de acordo com esses dados. Havendo, desta maneira, uma separação entre os indivíduos que não apresentavam, dos que apresentavam doença periodontal, como também uma subdivisão entre os doentes, levando-se em consideração o grau de severidade e a extensão da periodontopatia apresentada. Todos os indivíduos participantes tinham entre 18 e 72 anos e eram de ambos os gêneros.

\subsection{Critérios de inclusão e exclusão}

Os participantes do estudo foram orientados a não consumirem álcool no dia que antecedeu a coleta. Os critérios de inclusão da pesquisa foram não possuir qualquer tipo de doença sistêmica, ou estar acometido no momento da coleta sanguínea, por algum processo infeccioso ou inflamatório, sendo este verificado quando constatada alteração das contagens total e diferencial de leucócitos no hemograma compatíveis com infecção.

Como critérios de exclusão foram considerados a apresentação de alguma doença sistêmica, apresentar infecção, gestantes, lactantes, diabéticos, fumantes e aqueles que estão em uso de algum medicamento que cause alterações nos níveis de PCR (AINEs, AIEs, anticoncepcionais e estatinas). 


\subsection{Aspectos éticos}

O termo de consentimento livre e esclarecido foi devidamente preenchido pelos participantes da pesquisa, como rege a legislação pertinente, como também foram claramente explicados os procedimentos realizados e o objetivo dos mesmos. A pesquisa também contou com o preenchimento de um questionário para a coleta dos dados dos pacientes, como gênero, idade, presença de doenças pré e coexistentes, uso de medicamentos, dentre outros.

. Este estudo foi submetido previamente ao sistema eletrônico Plataforma Brasil para apreciação do Comitê de Ética em Pesquisa envolvendo seres humanos, sendo aprovado com o número de parecer 3.019.979.

\subsection{Coleta de sangue}

A coleta do sangue foi realizada por punção venosa. Estando os pacientes em jejum de 8 horas, sendo inicialmente realizada a antissepsia do local a ser puncionado, com álcool à 70\%. Logo após, utilizando-se equipamentos de proteção individual, garrote, seringas e agulhas descartáveis, o sangue foi coletado e depositado em dois tubos de vidro, com e sem anticoagulante, de acordo com a finalidade do material coletado. As amostras foram devidamente acondicionadas e enviadas ao laboratório para as análises bioquímicas. As análises hematológicas foram realizadas em um laboratório particular da cidade de Patos-PB.

\subsection{Avaliação quantitativa de PCR}

A análise quantitativa da Proteína C-Reativa foi realizada por imunoturbidimetria utilizando o kit Labtest ${ }^{\circledR}$. Para a análise, a amostra de sangue sem anticoagulante foi previamente centrifugada para a separação do soro, que foi utilizado como amostra. Ao serem adicionados os reagentes, partículas de látex estabilizadas e sensibilizadas com anticorpo Anti-Proteína CReativa (anti-PCR) humana aglutinaram com a PCR presente na amostra. A intensidade da aglutinação, medida em absorbância, foi proporcional à quantidade de PCR contida na amostra. A medida foi efetuada em espectrofotômetro segundo as recomendações do kit.

\subsection{Avaliação de risco cardiovascular}

$\mathrm{Na}$ avaliação de risco para eventos cardiovasculares, em especial coronarianos, os valores de referência foram aqueles preconizados pela American Heart Association, os quais foram determinados a partir de dados epidemiológicos. Sendo considerados valores de baixo risco cardiovascular aqueles menores que 1,0 mg/l, de risco médio, aqueles entre 1,0 e 3,0 mg/l e de alto risco, aqueles superiores a 3,0 $\mathrm{mg} / \mathrm{l}$ (Goff et al., 2014).

\subsection{Investigação do hemograma}

Para a análise do hemograma, o sangue foi depositado em tubo com o anticoagulante EDTA (ácido etilenodiaminotetracético), sendo esta amostra processada de maneira computadorizada. Para a avaliação das séries vermelha, branca e plaquetária. Sendo este um valioso mecanismo para a verificação do estado de saúde geral do participante da pesquisa. A avaliação da série branca serviu de parâmetro para avaliação de ocorrência de processos infecciosos, sendo estes parte dos critérios de exclusão.

\subsection{Análise estatística}

Os valores foram expressos como média mais ou menos o erro padrão da média (e.p.m.). Para a análise estatística, foram realizados os testes "t" de Student (não pareado) e análise de variância (ANOVA) "one-way" com o pós-teste de Dunnet. 
Diferenças entre grupos em que $\mathrm{p}<0,05$ foram consideradas significantes. Para as análises estatísticas foi utilizado o programa Graph Pad Prism versão 6.2.0.

\section{Resultados}

\subsection{Caracterização da amostra}

Os resultados abaixo apresentados são correspondentes às amostragens realizadas no período de novembro de 2018 a julho de 2019, onde foram coletados dados de 66 pacientes. Ao caracterizar os participantes da pesquisa, verificou-se que 54,54\% eram do gênero feminino e $45,45 \%$ do gênero masculino. No tocante à análise de cada grupo, separadamente, também se constatou predomínio na quantidade de mulheres (Tabela 1).

Tabela 1 - Divisão dos participantes da pesquisa de acordo com o gênero.

\begin{tabular}{|c|c|c|c|c|c|c|}
\cline { 2 - 7 } \multicolumn{1}{c|}{} & \multicolumn{3}{c|}{$\mathrm{n}$} & \multicolumn{3}{c|}{$\%$} \\
\cline { 2 - 7 } \multicolumn{1}{c|}{} & TESTE & CONTROLE & TOTAL & TESTE & CONTROLE & TOTAL \\
\hline MASCULINO & 13 & 14 & 27 & 19,69 & 21,21 & 40,90 \\
\hline FEMININO & 17 & 22 & 39 & 25,75 & 33,33 & 59,10 \\
\hline TOTAL & 30 & 36 & 66 & 45,45 & 54,54 & 100 \\
\hline
\end{tabular}

Fonte: Autores.

Em relação a idade média dos participantes da pesquisa foi constatada uma diferença estatisticamente relevante, sendo de 24,1 \pm 1,74 anos para o Grupo Controle, e de 32,4 \pm 2,41 anos para o grupo Doença Periodontal (Gráfico 1).

Gráfico 1 - Média de idade dos participantes da pesquisa.

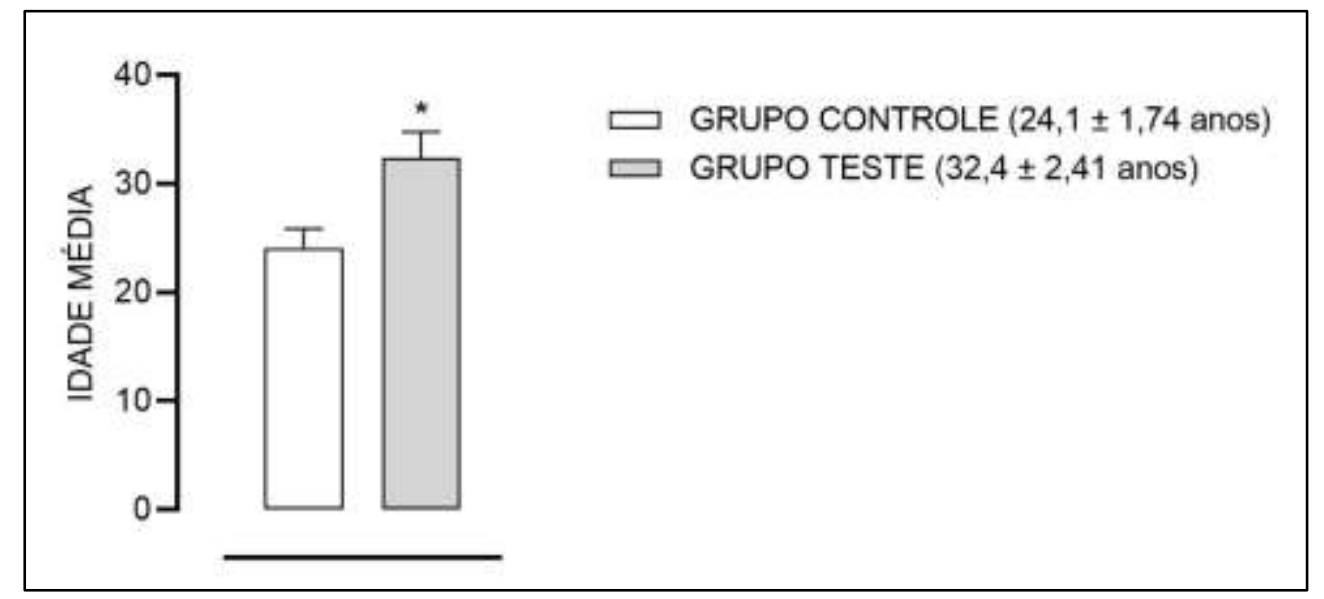

Os resultados foram expressos como média \pm erro padrão da média. Controle $\mathrm{n}=36$ e Teste $\mathrm{n}=30$. Foi realizado o teste " $t$ " de student não pareado. $(* \mathrm{p}<0,05$ comparado ao controle). Fonte: Autores.

No tocante a divisão dos participantes do Grupo Doença Periodontal e levando-se em consideração o tipo de doença periodontal à qual estavam sendo acometidos, verificou-se que 73,3\% apresentavam Gengivite e 16,6\% apresentavam Periodontite Localizada e 10,0\% com Periodontite Generalizada (Tabela 2). 
Tabela 2 - Divisão dos participantes do Grupo Doença Periodontal conforme o tipo de patologia periodontal apresentada.

\begin{tabular}{|c|c|c|}
\hline \multicolumn{1}{|c|}{} & $\mathrm{n}$ & $\%$ \\
\hline GENGIVITE & 22 & 73,3 \\
\hline PERIODONTITE LOCALIZADA & 05 & 16,6 \\
\hline
\end{tabular}

Fonte: Autores.

\subsection{Avaliação do risco cardiovascular}

Foram avaliados os níveis de PCR no soro pelo método ultrassensível, onde observou-se que as concentrações dessa biomolécula foram significantemente menores no grupo controle $(2,39 \pm 0,55 \mathrm{mg} / \mathrm{l} ; \mathrm{n}=42)$ em relação ao grupo com doença periodontal $(6,09 \pm 1,34 \mathrm{mg} / \mathrm{l} ; \mathrm{n}=40)($ Gráfico 2).

Gráfico 2 - Valores de PCR sérica nos grupos controle e com doença periodontal.

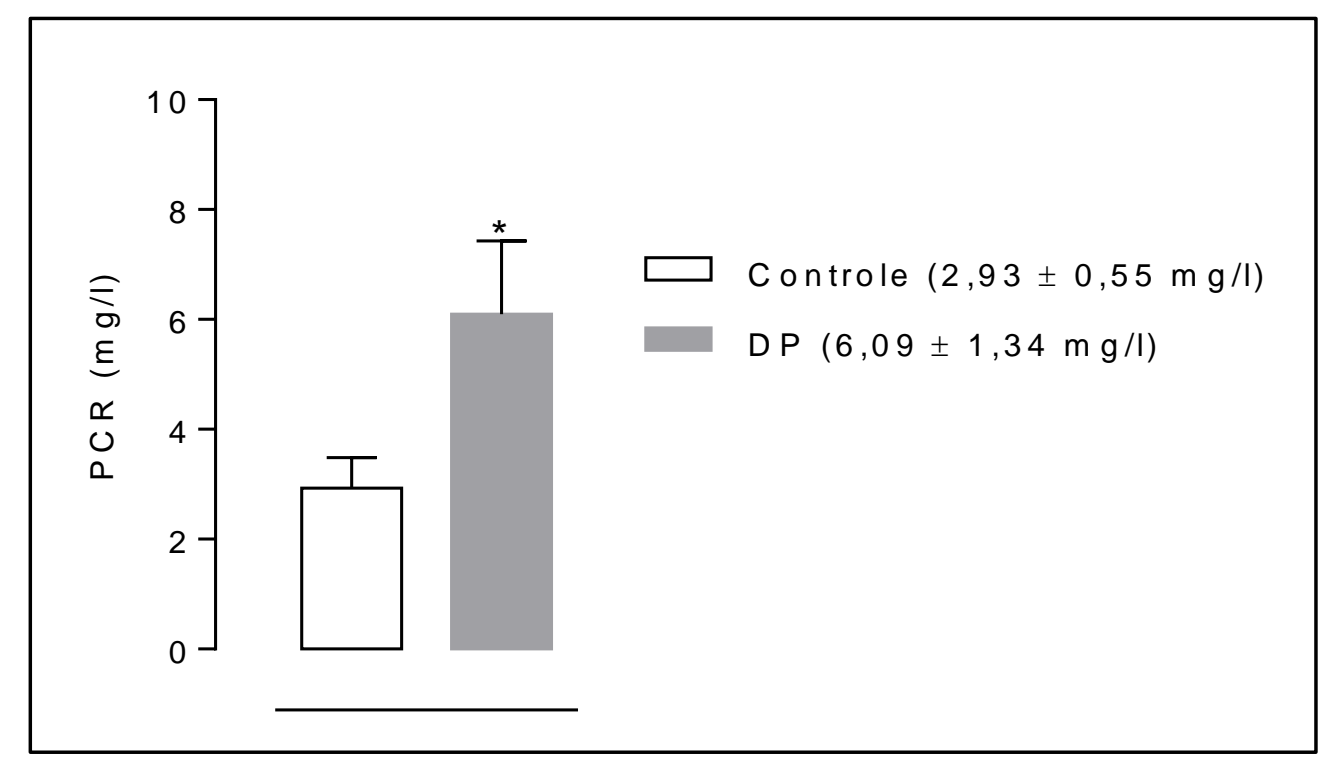

Os resultados foram expressos como média \pm erro padrão da média. Controle $\mathrm{n}=36$ e DP $\mathrm{n}=30$. Foi realizado o teste " $t$ " de student não pareado. $(* \mathrm{p}<0,05$ comparado ao controle). Fonte: Autores.

Ao serem avaliados os dados referentes à mensuração dos níveis séricos de PCR de acordo com a gravidade da doença periodontal, observou-se que os grupos com Gengivite $(6,95 \pm 1,99 \mathrm{mg} / \mathrm{l} ; \mathrm{n}=22)$ e com Periodontite Localizada $(11,82 \pm 5,27$ $\mathrm{mg} / \mathrm{l} ; \mathrm{n}=5)$ apresentaram valores de PCR significantemente maiores, em comparação aqueles do grupo Controle $(2,21 \pm 0,23$ $\mathrm{mg} / \mathrm{l} ; \mathrm{n}=36)$. Não foram observadas diferenças entre os valores do grupo com Periodontite Generalizada $(2,98 \pm 1,63 \mathrm{mg} / \mathrm{l} ; \mathrm{n}=$ 3) em relação ao grupo Controle. Desta forma, o grupo Controle e o grupo com Periodontite Generalizada apresentaram média de valores na faixa de risco cardiovascular moderado, enquanto os grupos com Gengivite e com Periodontite Generalizada apresentaram valores característicos de risco cardiovascular alto (Gráfico 3). 
Gráfico 3 - Valores de PCR sérica nos grupos Controle, com Gengivite, com Periodontite Localizada e com Periodontite Generalizada.

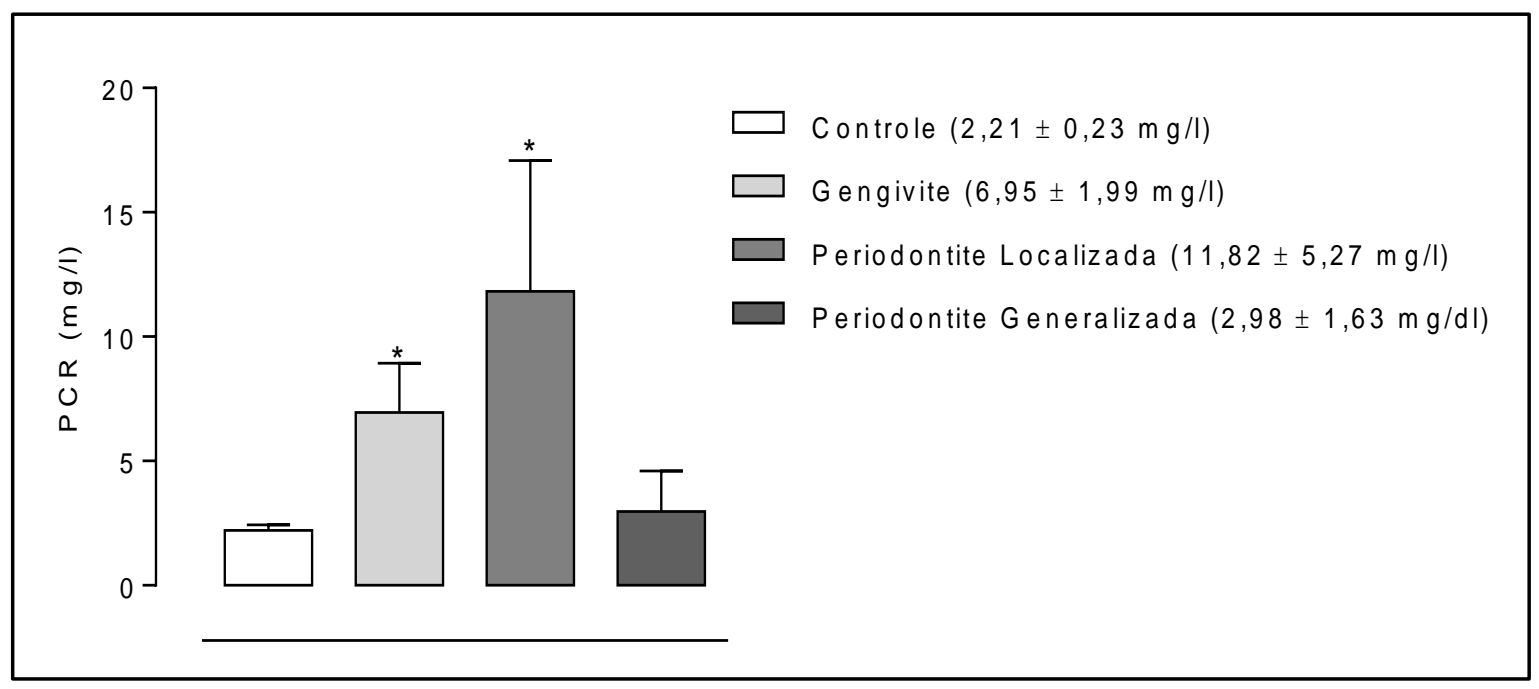

Os valores foram expressos como média \pm e.p.m. ${ }^{*} \mathrm{p}<0,05$ versus controle. Fonte: Autores.

Em se tratando da avaliação do risco cardiovascular, no grupo Controle foi verificado que 9 de seus integrantes apresentaram alto risco cardiovascular (25,0\%), 24 apresentaram risco cardiovascular moderado (66,6\%) e 3 apresentaram níveis de baixo risco cardiovascular (8,3\%). Analisando-se o grupo DP, constatou-se que 17 de seus integrantes enquadravam-se no patamar de alto risco cardiovascular $(56,6 \%), 12$ na faixa do risco moderado $(40,0 \%)$ e apenas um participante encontrava-se no baixo risco cardiovascular $(3,4 \%)$.

\section{Discussão}

Os principais achados deste trabalho foram que os pacientes do grupo controle apresentaram valores de PCR compatíveis com risco cardiovascular moderado, enquanto aqueles do grupo DP apresentaram valores compatíveis com risco cardiovascular elevado. Observou-se ainda que os pacientes com gengivite e periodontite localizada apresentaram valores de PCR significantemente maiores que aqueles dos grupos controle e com periodontite generalizada. Assim, os indivíduos dos grupos com gengivite e periodontite localizada tiveram valores compatíveis com um risco cardiovascular alto, enquanto os demais grupos podem ser classificados como de risco moderado.

Os resultados observados são concordantes com outros estudos realizados anteriormente quanto à relação entre os níveis séricos da PCR mais elevados em pacientes com doença periodontal, como também o risco cardiovascular mais acentuado apresentado pelos mesmos. Tal relação se justifica devido a bacteremia transitória decorrente das mudanças teciduais provocadas pela resposta inflamatória oriunda da doença periodontal.

Rodrigues-Neto et al. (2020) realizaram uma pesquisa para avaliar as concentrações séricas da PCR em pacientes com e sem doença periodontal, como também se ocorre alguma alteração na concentração dessa biomolécula após o tratamento periodontal não cirúrgico. Os mesmos concluíram que os indivíduos com doença periodontal apresentavam níveis séricos de PCR maiores em comparação com os de periodonto saudável e que o tratamento das periodontopatias promove a diminuição da PCR sérica.

Ide et al. (2004) conduziram um estudo que avaliou se injúrias subgengivais eram capazes de provocar elevação da PCR em indivíduos com doença periodontal, onde amostras de sangue venoso foram coletadas alternadamente durante certo intervalo de tempo, sendo constatado que houve elevação dos níveis séricos de fator de necrose tumoral alfa (TNF-alfa) e IL-6, resultado condizente com a bacteremia inicialmente cogitada. 
Outro estudo da mesma época demonstrou que pacientes que apresentavam maiores perdas dentárias associadas a níveis de perda de inserção mais acentuados, apresentavam maior risco cardiovascular quando comparados a pacientes com maior quantidades de dentes e com menores perdas de inserção (Elter et al., 2004).

Barilli et al., (2006) realizaram um estudo com pacientes que apresentavam cardiopatias isquêmicas, no intuito de verificar se havia relação entre o quadro cardiovascular dos mesmos e a doença periodontal, os resultados demonstraram uma elevada prevalência da doença periodontal com grau de severidade avançada, nos indivíduos acometidos pela doença isquêmica coronariana.

No tocante às disfunções endoteliais e inflamações sistêmicas, Amar et al., (2003) realizaram um estudo para mensurar o grau de dilatação dos vasos sanguíneos em indivíduos com e sem doença periodontal, onde constataram que os participantes que possuíam doença periodontal exibiam uma disfunção endotelial evidente, prejudicando o correto mecanismo de dilatação vascular, deixando-os mais propensos ao desenvolvimento de doenças cardiovasculares.

Diversos estudos apontam que, ao conseguirem acesso à corrente sanguínea, microorganismos que deveriam se restringir à cavidade oral, podem afetar as diversas áreas do organismo, promovendo o início de processos inflamatórios sistêmicos e mecanismos pró-trombólicos. O endotélio vascular mostra-se como uma destas áreas afetadas, onde se dissemina um processo inflamatório que associado a quadros de hiperlipidemia coexistentes, promovem a situação perfeita para o desenvolvimento da aterosclerose e posteriores manifestações patológicas decorrentes da mesma (Mastragelopulos et al., 2002; Pires et al., 2013).

Outro estudo buscou evidenciar o papel de patógenos associados com a doença periodontal, na ativação da coagulação sanguínea e mecanismos pró-trombólicos, onde foi possível evidenciar que microorganismos, como Porphyromona gingivalis e Streptococcus sanguis possuem a capacidade de induzir a formação de coágulos e posteriores trombos, fatores associados aos episódios de isquemia cardíaca característicos das cardiopatias (Accarini \& de Godoy, 2006).

Bale et al., (2017) realizaram um estudo onde evidenciaram que os patógenos de alta capacidade de invasão tecidual por via hematogênica que provocam a manifestação da doença periodontal, como a Aggregatibacter actinomycetemcomitans, geralmente associada a casos de Periodontite Agressiva, Porphyromonas gingivalis, Tannerella forsythia, Treponema denticola ou Fusobacterium nucleatum. possuem forte contribuição para a ocorrência de cardiopatias, ao ponto que os mesmos potencializam negativamente a tríade da patogênese aterosclerótica, elevando as concentrações plasmáticas da apolipoproteína B (ApoB), aumentando a permeabilidade vascular e progressiva degeneração endotelial e aumentam a ligação de lipoproteínas à camada íntima da parede vascular.

Oliveira et al., (2010) investigaram a influência exercida pelos processos infeciosos e inflamatórios resultantes da doença periodontal sobre sítios distantes, provocando repercussões sistêmicas como doenças cardiovasculares. Os pesquisadores concluíram que indivíduos que apresentavam simultaneamente doença coronariana isquêmica aguda e doença periodontal, possuem um quadro de desregulação lipídica e a presença de micro-organismos circundantes no sistema cardiovascular.

O processo inflamatório decorrente da doença periodontal, como também as agressões provocadas pelas endotoxinas das bactérias do biofilme periodontopatogênico, provocam alterações importantes em mediadores químicos do organismo do indivíduo. Assim, certas moléculas servem como marcadores para o diagnóstico e acompanhamento de quadros patológicos, como o risco cardiovascular e a própria doença periodontal. A PCR figura como um destes marcadores, sendo o mesmo produzido em baixas quantidades em estados de equilíbrio fisiológico do organismo. Porém, na presença de processos inflamatórios e infecciosos na fase aguda, a PCR sofre um aumento abrupto na sua produção.

Devido a sua alta prevalência na população como também pelos fatores de risco que são comuns às duas patologias, um estudo comparativos de diversas bases de dados bibliográficos concluiu que níveis elevados da PCR (> 2,1mg/l) possuem 
confiabilidade para que as mesmas sejam utilizadas como um marcador para o risco aterosclerótico e portanto, um preditor para a constatação do risco cardiovascular (Bălan, 2010).

Muito frequentes na atualidade, alguns estudos têm demostrado o verdadeiro papel e importância da PCR, na relação entre a doença periodontal e o aumento do risco cardiovascular, onde a proteína encontra-se diretamente associada ao processo aterosclerótico (Silva \& Lacerda, 2012).

Spezzia e Calvoso Júnior, (2013) efetuaram uma pesquisa nas principais bases de dados bibliográficos de estudo, como Pubmed, Scopus, Lilacs, no intuito de investigar a relação entre a doença periodontal, risco cardiovascular e a PCR, onde constataram que a doença periodontal e a doença cardiovascular são bastante prevalentes, dividindo fatores de risco semelhantes, tais como idade, hábito de fumar, estresse, nível socioeconômico, obesidade, entre outros. Outro fato apontado é que pode ocorrer associação entre doença periodontal e doença cardiovascular de diversas formas diferentes, como pelo efeito discreto dos agentes infecciosos presentes no biofilme dentário, participando na formação da placa de ateroma, efeitos indiretos ou mediados pelo hospedeiro acionados pela infecção periodontal, predisposição genética, comum para ambas as doenças e fatores de risco comuns para as duas patologias.

Lima et al., (2007) realizaram um estudo onde no qual foi avaliada a concentração sérica da PCR de acordo com a grau de severidade da doença cardiovascular apresentada pelo indivíduo, constatando-se que existe uma relação crescente onde pessoas isentas de cardiopatias possuem menores valores da PCR sérica quando em comparação a indivíduos que apresentam doenças cardiovasculares em estágios de maior severidade.

Outro estudo que faz uso da mensuração dos níveis séricos da PCR foi realizado por Zanella et al., (2012), onde 206 indivíduos sem diagnóstico de doença arterial coronária (DAC) foram avaliados através de exames clínicos periodontais, exames hematológicos (glicemia, perfil lipídico e PCR) e cineangiocoronografia. Os resultados obtidos apontaram que não houve diferença entre os biomarcadores inflamatórios dos pacientes sadios, quando em comparação aos pacientes com diagnóstico de DAC, porém o edentulismo foi mais prevalente nos pacientes com DAC, o que os levou a concluir que o comprometimento da saúde bucal possui relação com a condição cardiovascular.

No entanto, Domingues et al., (2013) realizaram um estudo para avaliar a relação existente entre marcadores de risco cardiovascular e a periodontite, porém não conseguiram observar diferenças estatisticamente significantes entre as concentrações séricas da PCR em pacientes com e sem doença periodontal.

Outro estudo de importância foi realizado por Blauth et al., (2008) no intuito de investigar a existência de associação entre os níveis séricos da PCR e fatores de risco cardiovascular em um grupo mulheres idosas, onde constataram que os níveis da PCR encontravam-se fortemente associados a marcadores da obesidade, sem no entanto apresentarem algum tipo de afinidade com outros fatores de risco cardiovascular.

Desta forma tem-se que nem sempre as concentrações séricas da PCR estarão mais elevadas nos indivíduos que apresentam a doença periodontal quando em comparação aos que não a possuem. Porém, um estudo demonstrou que não há obrigatoriedade na relação de indivíduos acometidos pela doença periodontal apresentarem sempre níveis da PCR no soro mais elevados que indivíduos sadios, entretanto, estes tiveram a doença periodontal como fator decisivo para uma maior propensão para o desenvolvimento de doenças cardiovasculares (Bezerra, 2007).

Goulart et al., (2017) buscaram avaliar a relação entre a doença periodontal e as doenças cardiovasculares, porém não observaram nenhuma associação estatisticamente relevante diante dos resultados encontrados.

Diante disto verifica-se que não há um consenso na literatura que demonstre a incontestável relação entre as dosagens mais elevadas da PCR em indivíduos com doença periodontal em comparação com indivíduos de periodonto saudável, necessitando a realização de estudos de maior magnitude, onde será possível a análise de uma amostra maior, para que haja um resultado de maior confiabilidade. 


\section{Conclusão}

Foi constatado que os pacientes que apresentavam a doença periodontal apresentavam níveis séricos significantemente mais elevados da PCR, tendo os mesmos maior risco de desenvolvimento de cardiopatias quando em comparação aos indivíduos do grupo controle, que estavam isentos de periodontopatias. Observou-se ainda que o risco mais elevado foi observado nos pacientes com gengivite e com periodontite localizada. Estes resultados mostram um risco aumentado de desenvolvimento de eventos cardiovasculares em indivíduos que apresentam doenças periodontais.

Para o contínuo avanço do conhecimento científico na área em questão, sugerimos que mais estudos sejam realizados, tendo uma maior amostragem e magnitude, principalmente no tocante a indivíduos acometidos com doenças periodontais em estágios mais severos. No intuito da obtenção de resultados mais fidedignos e de maior confiabilidade.

\section{Referências}

Accarini, R., \& de Godoy, M. F. (2006). Doença Periodontal como Potencial Fator de risco para síndromes Coronarianas Agudas. Arquivos Brasileiros de Cardiologia, 87(5), 592-596.

Amar, S., Gokce, N., Morgan, S., Loukideli, M., Van Dyke, T. E., \& Vita, J. A. (2003). Periodontal disease is associated with brachial artery endothelial dysfunction and systemic inflammation. Arteriosclerosis, Thrombosis, and Vascular Biology, $23(7)$, $1245-1249$. https://doi.org/10.1161/01.ATV.0000078603.90302.4 ${ }^{\mathrm{a}}$

Bălan, H. (2010). Do cardio-vascular and periodontal diseases have a close, causal relationship? Romanian Journal of Internal Medicine, 48(2), 121-129.

Bale, B. F., Doneen, A. L., \& Vigerust, D. J. (2017). High-Risk periodontal pathogens contribute to the pathogenesis of atherosclerosis. Postgraduate Medical Journal, 93(1098), 215-220. https://doi.org/10.1136/postgradmedj-2016-134279

Bansal, T., Pandey, A., Deepa, D., \& Asthana, A. K. (2014). C-Reactive Protein (CRP) and its Association with Periodontal Disease: A Brief Review. Journal of Clinical and Diagnostic Research, 8(7), 21-24. https://doi.org/10.7860/JCDR/2014/8355.4646

Barilli, A. L. A., Passos, A. D. C., Marin-Neto, J. A., \& Franco, L. J. (2006). Doenças periodontais em pacientes com doença isquêmica coronariana aterosclerótica, em Hospital Universitário. Arquivos Brasileiros de Cardiologia, 87(6), 695-700.

Bascones-Martínez, A., Bascones-Ilundain, J., \& Bascones-Ilundain, C. (2017). Medicina periodontal (III): Enfermedad cardiovascular y Síndrome metabólico. Avances en Periodoncia e Implantología Oral, 29(3), 109-119.

Bezerra, C. F. R. (2007). Avaliação dos níveis de Proteina C-Reativa Ultra-Sensível em pacientes com periodontite crônica severa generalizada e sem periodontite. 81p. Dissertação (Mestrado em Odontologia / Periodontia). Universidade Federal do Rio Grande do Norte, Natal, 2007. https://repositorio.ufrn.br/handle/123456789/17097

Bezerra, C. F. R., Amaral, B. A. do, Camelo, F. P., Aquino, A. R. L. de, Seabra, E. G., \& Carreiro, A. da F. P. (2008). O Papel da Proteína C-Reativa na relação entre as doenças periodontais e cardiovasculares. Revista Periodontia, 18(1), 7-13.

Black, S., Kushner, I., \& Samols, D. (2004). C-reactive Protein. Journal of Biological Chemistry, 279(47), 48487-48490. https://doi.org/10.1074/jbc.R400025200

Blauth, F., Lara, G. M., Wagner, S. C., \& Reichert, C. L. (2008). Associação entre fatores de risco cardiovascular e proteína C-reativa em mulheres idosas. Jornal Brasileiro de Patologia e Medicina Laboratorial, 44(2), 83-88. https://doi.org/10.1590/S1676-24442008000200004

Chen, Y., Wu, S., Li, W., Wang, B., Han, X., Yang, Y., Guan, X., Yu, H., Khalid, B. W., Li, H., \& Xia, Y. (2018). Higher high-sensitivity C-reactive Protein is associated with future premature ventricular contraction: a community based Prospective Cohort Study. Scientific Reports, 8(1), 1-7. https://doi.org/10.1038/s41598-018-22868-8

Domingues, J. E. G., Vettore, M. V., \& Lima, E. S. (2013). Association between markers of cardiovascular risk and clinical parameters of periodontitis. Revista de Odontologia da UNESP, 42(5), 336-343. https://doi.org/10.1590/s1807-25772013000500004

Elter, J. R., Champagne, C. M. E., Offenbacher, S., \& Beck, J. D. (2004). Relationship of periodontal disease and tooth loss to prevalence of coronary heart disease. Journal of Periodontology, 75(6), 782-790. https://doi.org/10.1902/jop.2004.75.6.782

Estrela, C. (2005). Metodologia científica: ciência, ensino, pesquisa. (2a ed.), Editora Artes Médicas. 707 p.

Goff, D. C., Lloyd-Jones, D. M., Bennett, G., Coady, S., D’Agostino, R. B., Gibbons, R., Greenland, P., Lackland, D. T., Levy, D., O’Donnell, C. J., Robinson, J. G., Schwartz, J. S., Shero, S. T., Smith, S. C., Sorlie, P., Stone, N. J., \& Wilson, P. W. F. (2014). 2013 ACC/AHA guideline on the assessment of cardiovascular risk: A report of the American college of cardiology/American heart association task force on practice guidelines. Circulation, 129(25), 49-73. https://doi.org/10.1161/01.cir.0000437741.48606.98

Goulart, A. C., Armani, F., Arap, A. M., Nejm, T., Andrade, J. B., Bufarah, H. B., \& Dezen, D. H. S. (2017). Relationship between periodontal disease and cardiovascular risk factors among young and middle-aged Brazilians. Cross-sectional study. São Paulo Medical Journal, 135(3), 226-233. https://doi.org/10.1590/1516-3180.2016.0357300117

Ide, M., Jagdev, D., Coward, P. Y., Crook, M., Barclay, G. R., \& Wilson, R. F. (2004). The short-term effects of treatment of chronic periodontitis on circulating 
Research, Society and Development, v. 11, n. 3, e34411326492, 2022

(CC BY 4.0) | ISSN 2525-3409 | DOI: http://dx.doi.org/10.33448/rsd-v11i3.26492

levels of endotoxin, C-reactive Protein, Tumor Necrosis Factor- $\alpha$, and Interleukin-6. Journal of Periodontology, 75(3), 420-428. https://doi.org/10.1902/jop.2004.75.3.420

Li, S., Mason, C. E., \& Melnick, A. (2016). Genetic and epigenetic heterogeneity in acute myeloid leukemia. Current Opinion in Genetics \& Development, 36(2), 100-106. https://doi.org/10.1016/j.gde.2016.03.011

Lima, L. M., Carvalho, M. D. G., Loures-Vale, A. A., Neto, C. P. D. F., Garcia, J. C. D. F., Saad, J. A., \& Sousa, M. O. (2007). Proteína C-reativa ultra-sensível em pacientes com diagnóstico de doença arterial coronariana estabelecido por angiografia. Jornal Brasileiro de Patologia e Medicina Laboratorial, 43(2), 8386. https://doi.org/10.1590/s1676-24442007000200003

Linden, G. J., Lyons, A., \& Scannapieco, F. A. (2013). Periodontal systemic associations: Review of the evidence. Journal of Clinical Periodontology, 40(14), 8-19. https://doi.org/10.1111/jcpe.12064

Mastragelopulos, N., Haraszthy, V. I., Zambon, J. J., \& Zafiropoulos, G. G. (2002). Nachweis parodontal pathogener mikroorganismen in atheromatösen plaques: Vorläufige Ergebnisse. Chirurg, 73(6), 585-591. https://doi.org/10.1007/s00104-001-0385-1

Oliveira, F. J. de, Vieira, R. W., Coelho, O. R., Petrucci, O., Oliveira, P. P. M. de, Antunes, N., Oliveira, I. P. F. de, \& Antunes, E. (2010). Inflamação sistêmica causada pela periodontite crônica em pacientes vítimas de ataque cardíaco isquêmico agudo. Revista Brasileira de Cirurgia Cardiovascular, 25(1), 51-58. https://doi.org/10.1590/s0102-76382010000100013

Pires, J. R., Dezem, T. U., Barroso, E. M., Toledo, B. E. C. de, Monteiro, S. C. M., Martins, A. T., \& Zuza, E. P. (2013). Cardiovascular risk in obese patients with chronic periodontitis: a clinical controlled study. Revista de Odontologia da UNESP, 42(3), 188-195. https://doi.org/10.1590/s1807-25772013000300008

Preshaw, P. M., \& Taylor, J. J. (2011). How has research into cytokine interactions and their role in driving immune responses impacted our understanding of periodontitis? Journal of Clinical Periodontology, 38(11), 60-84. https://doi.org/10.1111/j.1600-051X.2010.01671.x

Rodrigues-Neto, S. da C., Oliveira, E. N. de, Martins, B. A., Silva, I. L., Souza Júnior, A. M. de, Jerônimo, R. de L., Sousa, J. N. L. de, \& Alves, M. A. S. G. (2020). Avaliação da influência da doença periodontal sobre os níveis séricos de proteína C-reativa. Research, Society and Development, 9(8), 1-17. https://doi.org/10.33448/rsd-v9i8.5310

Silva, D., \& Lacerda, A. P. de. (2012). Proteína C-Reativa de alta sensibilidade como biomarcador de risco na doença coronária. Revista Portuguesa de Cardiologia, 31(11), 733-745. https://doi.org/10.1016/j.repc.2012.02.018

Simão, A. F., Precome, D. B., Andrade, J. P., Correa Filho, H., Saraiva, J. F. K., Oliveira, G. M. M., Murro, A. L. B., Campos, A., Alessi, A., Avezum Junior, A., Achutti, A. C., Miguel, A. C. M. G., Souza, A. C. S., Lotemberg, A. M. P., Lins, A. P., Falud, A. A., Brandão, A. A., Sanjuliani, A. F., Sbissa, A. S., \& Souza, W. K. S. B. (2013). I Diretriz brasileira de prevenção cardiovascular. Revista da Sociedade Brasileira de Cardiologia, 101(6), 1-63. https://doi.org/10.5935/abc.2013S012

Spezzia, S., \& Calvoso Júnior, R. (2013). Proteína C-reativa , aterosclerose e doenças periodontais. Brazilian Journal of Surgery and Clinical Research-BJSCR, 4(1), 63-67. http://www.mastereditora.com.br/bjscr

Zanella, S. M., de Souza, L. V., Suzigan, B. H., Saba-Chujfi, E., \& Barbisan, J. N. (2012). Associação entre saúde bucal e doença arterial coronária aterosclerótica em pacientes submetidos a cineangiocoronariografia: Estudo transversal controlado. Revista Brasileira de Cardiologia Invasiva, 20(2), 178-183. https://doi.org/10.1590/s2179-83972012000200012 